\title{
Compositions and properties of microbial residues formed by three single species fungi and mixed strains in cellulose- containing liquid media
}

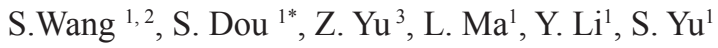 \\ ${ }^{1}$ College of Resource and Environmental Science, Jilin Agricultural University, Changchun 130118, China. ${ }^{2}$ Institute of Plant \\ Sciences, Jilin Agricultural Science and Technology College, Jilin 132101, China. ${ }^{3}$ Hydrology Group, Institute of Landscape \\ Ecology, University of Münster, Heisenbergstr. 2, Muenster, 48149, Germany. *Corresponding authors: wangshuai419@126.com
}

\begin{abstract}
The microbial residues, due to their closely connection with humic substances (HS), aroused our considerable interest. The method of shake-flask in liquid culture was adopt to accumulate them, in which the cellulose served as the sole $\mathrm{C}$ source. The microbial suspensions including Trichoderma viride (Tv), Aspergillus niger (An), Penicillium $(P)$ and mixed strains $(M s)$ were inoculated into the cellulose culture fluid respectively. The incubation was performed for 70 days at a constant temperature of $28^{\circ} \mathrm{C}$. The results showed that different microbial treatments had different effects on the $\mathrm{C}$ turnover in the cellulose fluid, among which $M s$ performed the most effective role in accumulating microbial residue and consuming organic $\mathrm{C}$ of cell metabolic product, $T v$ followed. As compared to cellulose, large amounts of inorganic $\mathrm{N}$ in the fluid could be transferred into the organic $\mathrm{N}$ components of residue. In the mean time, the proportion of aromatic rings could be increased at the cost of losing O-containing groups. Specifically, the degrees of condensation were enhanced by $T v$ and $A n$, however their degrees of oxidation were inhibited. On the contrary, the $\mathrm{P}$ and Ms treatments had a significant advantage in the oxydative degradation of cellulose. Although some intermediate products (polysaccharides, phenolic compounds, carboxylic groups and syringyl units etc.) of HS could be detected in the microbial residues treated by $T v$ and $A n$, their organic molecules did not still achieve the polymerization degree of real HS.
\end{abstract}

Keywords: fungi, mixed strains, cellulose, microbial residue, humic substances 


\section{Introduction}

Microbial residue represents a significant amount of soil organic matter (SOM) (Ding et al., 2013). Organic matter is widely regarded as a vital component of a healthy soil, and it is very important in the movement of nutrients in the environment. Their basic structures are created from cellulose, tannin, cutin and lignin, along with other various proteins, lipids, and carbohydrates. As the most abundant biopolymer, the cellulose is a linear polymer glucan and is composed of glucose units $(>10000)$ which are linked by $\beta-(1-4)$-glycosidic bonds (KögelKnabner, 2002). Large amounts of microbial residues are immediately formed after the addition of easily decomposable components such as cellulose (Vinten et al., 2002; Engelking et al., 2007a). The microbial tissue can be divided into biomass and residues, in which non-biomass microbial residues are comprised of exo-enzymes, mucous substances, other microbial metabolites and dead tissue (Engelking et al., 2007b). The addition of plant residue-derived substrates can make the microorganisms proliferate rapidly, and the rapid microbial growth is always coupled with concomitant microbial death (Chander and Joergensen, 2001). In this process, $C$ in plant residues can be assimilated into microbial biomass during their decomposition before incorporation into SOM in the form of microbial residues after cell death. The nonliving microbial residues were bound up with SOM pool and it can be related to SOM turnover (Ding et al., 2011). As an important part of the stable $\mathrm{C}$ pool in soils, the microbial residues can be difficult to attain complete separation to exhibit their compositions and properties.

Humic substances (HS) are the main constituent of the organic carbon pool in soil (SOM) as well as in stained aquatic ecosystems. Although HS in liquids have different characteristics to HS in soils, such as aquatic HS being more aliphatic (McDonald et al., 2004) and having higher degree of oxidation (Duarte et al., 2007), their chemical composition and structural characteristics appear to have many characteristics in common (McDonald et al., 2004). A deep understanding of cellulose biodegradation in liquid cultures will be indirectly helpful to explore a part of formation process of HS in soils.

Cellulose and lignin in plant structural material are often thought to be likely sources of precursor material for HS synthesis. However, Burdon (2001) pointed out the humification could also occur in plants that did not contain lignin. We have reasons to believe that cellulose serves as a sole substrate can promote the formation of HS or their essential component. Moreover, the cellulose can be degraded by the cellulase secreted from Trichoderma and Aspergillus (Singh and Sharma, 2002). It is concluded that no completely decomposed cellulose, we may call it leftovers, coupled with a lot of microbial debris, can constitute some indispensable precussor materials of HS formation, such as lipids and melanins which are quantitatively minor components of fungal cell walls (Kögel-Knabner, 2002).

The microbial residues, due to their closely connection with HS, had not as yet been properly chemically defined (McDonald et al., 2004), which could arouse our considerable interest. In view of difficulty in separating microbial residues from soil and their complexity, to explore their contribution to SOM based on different microbial species (three fungal species and mixed strains), the liquid pure culture had to be conducted, in the process cellulose served as a sole substrate.

Our objective was to evaluate how the different microbial treatments affected the compositions and properties of microbial residues accumulated in the cellulose-containing liquid media and their contribution to SOM. However, how this occured in the liquid solutions was less clear. The design allowed this to be explored. We would focus on the impact of different microbial treatments on the $\mathrm{C}$ cycling and hence the patterns of residues in fluids. 


\section{Material and Methods}

\subsection{Preparation of cellulose nutrient fluid and tested pure strains}

The preparation of cellulose nutrient fluid adopt the modified Czapek Dox Agar medium, whose recipe is as follows: $\mathrm{NaNO}_{3} 2.0 \mathrm{~g} \mathrm{~L}^{-1}, \mathrm{~K}_{2} \mathrm{HPO}_{4} 1.0 \mathrm{~g} \mathrm{~L}^{-1}, \mathrm{KCl} 0.5$ $\mathrm{g} \mathrm{L}^{-1}, \mathrm{MgSO}_{4} \cdot 7 \mathrm{H}_{2} \mathrm{O} 0.5 \mathrm{~g} \mathrm{~L}^{-1}, \mathrm{FeSO}_{4} 0.01 \mathrm{~g} \mathrm{~L}^{-1}$, sodium carboxymethyl cellulose $20 \mathrm{~g} \mathrm{~L}^{-1}$.

The combination of 16S rRNA gene sequences and conventional approach was adopt for species identification. Based on a specialized strain information databases GeneBank (NCBI) and an available website called "EzTaxon", the identification results revealed that strains examined were Brevibacterium sp (Similarity degree reached 99.5\%), Bacillus megaterium (100\%), Streptosporangium sp (99.6\%), Streptomyces sp (97.2\%), Trichoderma viride (99\%), Aspergillus niger and Penicillium, respectively.

The strains mentioned above were all isolated from a Luvic Phaeozem according to FAO/UNESCO that was collected from a field under monoculture maize at the experimental station of Jilin Agricultural University,

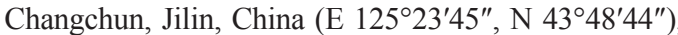
which were maintained and further cultured on Beef Extract Peptone, improved Gause's and Potato Dextrose Agar (PDA) plates respectively and stored at $4{ }^{\circ} \mathrm{C}$.

\subsection{Microbial suspensions preparation and experimental design}

Firstly, the seven single microbial suspensions needed be prepared. The pure strains with their mycelium and adherent spores on agar plate were scraped down and washed into a sterile container under absolutely aseptic conditions. And then, the mixed suspension was prepared by the mixture of seven single suspensions in equal proportions.

The method of shake-flask liquid culture was conducted in a shaking incubator that was set at 200 $\mathrm{r} / \mathrm{min}$ in a constant temperature environment $\left(28^{\circ} \mathrm{C}\right)$ for 70 days (d). Every $250 \mathrm{ml}$ Erlenmeyer flask with $100 \mathrm{ml}$ cellulose nutrient fluid, after an autoclaved process at $121^{\circ} \mathrm{C}$ for $20 \mathrm{~min}$ and being allowed to cool to room temperature, was inoculated $5 \mathrm{~mL}$ microbial suspension according to the specific requirements.

Five different microbial treatments were designed as: (1) Trichoderma viride (Tv); (2) Aspergillus niger (An); (3) Penicillium (P); (4) Mixed strains $(M s)$ and (5) No strain $(C K)$. The experiment was repeated twice, each time with six replicates per treatment. To ensure the total volume of culture flask, the regular weighing and moisture replenishment was necessary.

After a period of incubation time, the mixed medium in culture flask was centrifuged by $28620 \mathrm{~g}$ (12000 $\mathrm{r} / \mathrm{min}$ ) for $15 \mathrm{~min}$. The supernatant liquor obtained was cell metabolic product and the precipitation was deemed as microbial residue. The microbial residue should be dried at $55{ }^{\circ} \mathrm{C}$ and stored in vacuum dryer for further analysis.

\subsection{Elemental analysis}

The $\mathrm{C}, \mathrm{H}$, and $\mathrm{N}$ contents of microbial residue were determined by Elementar Vario ELIII elemental analyzer (Shimadzu TOC-VCPH, Japan). The O+S content was calculated by the subtraction method.

\subsection{FTIR spectroscopy}

The FTIR spectra were recorded on pellets obtained by pressing a mixture of about $1 \mathrm{mg}$ of microbial residue and $200 \mathrm{mg}$ of $\mathrm{KBr}$ under reduced pressure using a Nicolet Nexus FTIR spectrophotometer equipped with Nicolet Omnic 6.0 software package. Spectra were acquired in the $4000-400 \mathrm{~cm}^{-1}$ range with $2 \mathrm{~cm}^{-1}$ resolution, and 64 scans were performed on each acquisition (Zhang et al., 2011).

\subsection{Statistical analysis}

All statistical analyses were carried out using PASW Statistics 18.0. Multivariate (MANOVA) and oneway analysis of variance (ANOVA) were used in this 
experiment. The effects of two independent variables (microbial treatments and inoculation periods) on several dependent variables (Production rate, $\mathrm{C} / \mathrm{N}$, $\mathrm{H} / \mathrm{C}$ and $\mathrm{O} / \mathrm{C}$ ) are examined simutaneously. A twoway design enables us to examine the joint effect of independent variables. Mean comparison was performed through Duncan's test, at $p<0.05$.

\section{Results}

\subsection{Change of organic $C$ content in microbial} metabolites and the conversion rate of cellulose

As an available $\mathrm{C}$ source, addition of microbial suspensions could induce a true priming effect. The background contents of organic $\mathrm{C}$ in four microbial suspensions from Tv, An, P to Ms were 0.93, 0.72, 0.29 and $0.46 \mathrm{~g} \mathrm{~L}^{-1}$ respectively. After a period of incubation time, compared with $\mathrm{CK}$, the losses of organic $\mathrm{C}$ in the cellulose fluid were detected due to the microbial utilization (Figure 1).

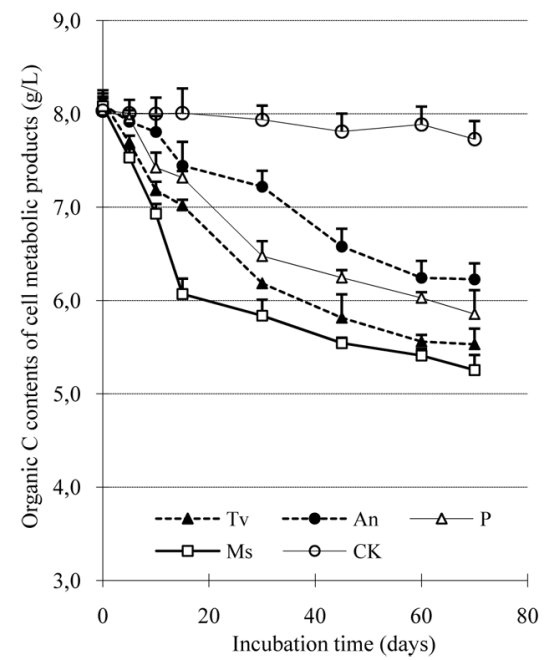

Figure 1. Dynamic changes in organic $\mathrm{C}$ contents of cell metabolic product during the whole incubation period (70 d) Trichoderma viride (Tv), Aspergillus niger (An), Penicillium $(P)$, Mixed strains $(M s)$, sterile treatment $(C K)$; Vertical bars represent standard deviation.
The declined process, which was analyzed in detail, could be divided into two stages: a) the first rapid stage (0-15d) and b) the later slow stage (15-70 d). The proportion of loss in organic $\mathrm{C}$ of residue treated by $M s$ at $15 \mathrm{~d}$ was $71.02 \%$ of its total loss, $T v$ (42.91 $\%)$ and $A n(34.76 \%)$ followed, and the least value presented by $P(32.88 \%)$. And then the contents of organic $\mathrm{C}$ experienced a continued slowdown until the end of culture. Finally, the order of losses in organic $\mathrm{C}$ contents of cell metabolic products was as follows: $M s>T v>P>A n$.

The transformed efficiency of organic $\mathrm{C}$ in the cellulose fluid that we called conversion rate was indirectly related to the degradation capacities of different microbial strains. The results were shown in Figure 2. In this process, $M s(34.97 \%)$ performed the most efficient conversion rate over the other three single fungal treatments (Tv $32.04 \%$, P $27.18 \%$ and An $23.15 \%$ ).

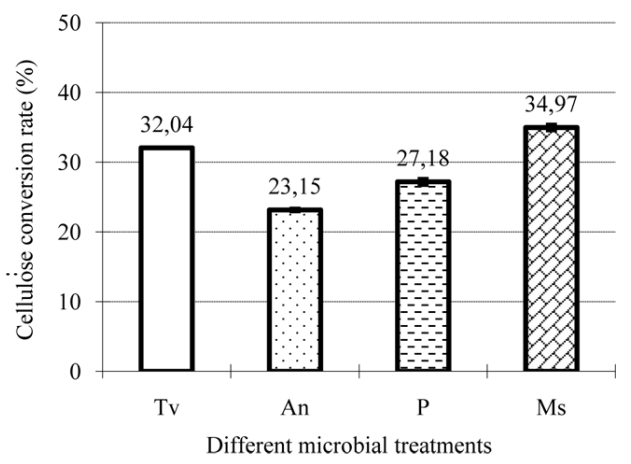

Figure 2. Effects of three single fungal species and mixed strains on the cellulose conversion rate Cellulose conversion rate $(\%)=[(\mathrm{C}$ content of original cellulose nutrient fluid - $\mathrm{C}$ content of microbial metabolites cultured for $70 \mathrm{~d}$ ) / C content of original cellulose nutrient fluid] $\times 100 \%$; Trichoderma viride $(T v)$, Aspergillus niger (An), Penicillium (P), Mixed strains $(M s)$. 


\subsection{Production rates of microbial residues and their elemental compositions}

As could be seen from Table 1, with incubation time increasing (15-70 d), the production rates increased gradually. The residue from $T v$ treatment, whose production rate increased from $2.474 \%$ to $2.952 \%$ over a period of $70 \mathrm{~d}$. Similar trends were observed in $A n(1.120 \%-1.172 \%), P(0.681 \%-1.061 \%)$ and Ms $(1.180 \%-2.019 \%)$ treatments. Obviously, the production rate obtained in the $T v$ treatment was the most, $M s$ took the second place, and the least was found in $P$ treatment. After a careful comparison, we found that the production rates obtained at $15 \mathrm{~d}$ could occupy an overwhelming majority of the results of $70 \mathrm{~d}$. The proportions of that were $T v 83.80 \%$, An $95.56 \%, P$ $64.18 \%$ and $M s 58.42 \%$, respectively. It was inferred that the production rates obtained from $A n$ and $T V$ tend to be constant in the period of 15-70 d, and the treatments of $M s$ and $P$ still keep a highly microbial activity and reproductive capacity in this period.

To further explore the compositions of microbial residues formed by three fungal species and mixed strains in the cellulose culture fluid, the elemental analysis was adopted, whose results were also shown in Table 1. The $\mathrm{C} / \mathrm{N}, \mathrm{H} / \mathrm{C}$ and $\mathrm{O} / \mathrm{C}$ ratios of the microbial residue formed by $T v$ were all increased slightly, and then decreased remarkably, in the end there was a declined trend found in their ratios. And the incubation of $A n$ resulted in a gradual decrease of $\mathrm{C} / \mathrm{N}$ and $\mathrm{O} / \mathrm{C}$ ratios in its residue, but its $\mathrm{H} / \mathrm{C}$ ratio experienced a process of increasing slightly and dropping significantly later. The $\mathrm{P}$ treatment was also helpful to reduce its $\mathrm{C} / \mathrm{N}$ ratio of residue gradually, on the contrary, both of their $\mathrm{H} / \mathrm{C}$ and $\mathrm{O} / \mathrm{C}$ ratios were enhanced, although there was no remarkable difference during the period of 15-30 d. Under the same condition, the $\mathrm{H} / \mathrm{C}$ and $\mathrm{O} / \mathrm{C}$ ratios were enhanced in the residue treated by $M s$, whereas its $\mathrm{C} / \mathrm{N}$ ratio had a increasing trend despite existing a small fluctuation at $30 \mathrm{~d}$.

Furthermore, compared with original cellulose, all the $\mathrm{C} / \mathrm{N}, \mathrm{H} / \mathrm{C}$ and $\mathrm{O} / \mathrm{C}$ ratios of microbial residues treated for $70 \mathrm{~d}$ by different microbial treatments were reduced significantly. The comparison among the microbial treatments told us the atomic ratios of $\mathrm{C} / \mathrm{N}$, $\mathrm{H} / \mathrm{C}$ and $\mathrm{O} / \mathrm{C}$ of microbial residue treated by $M s$ were all more than the other three single fungal treatments (Tv, An and $P$ ).

The percent of production rate, $\mathrm{C} / \mathrm{N}, \mathrm{H} / \mathrm{C}$ and $\mathrm{O} / \mathrm{C}$ ratios of microbial residues could be affected by microbial treatment, inoculation period and a microbial treatment $\times$ inoculation period interaction. To explore their correlation further, the repeated measures MANOVA was applied, the relevant parameters were listed in Table 2 and Table 3. It was clear that the $\mathrm{C} / \mathrm{N}$, $\mathrm{H} / \mathrm{C}$ and $\mathrm{O} / \mathrm{C}$ ratios of microbial residues be affected by both microbial treatments and inoculation periods, with statistical significance $(p<0.05)$.

In order to make clear the differences between microbial residue and humic fractions, we quoted the results of Suwannee River humic acid (SRHA) and fulvic acid (SRFA) standards from Duarte et al. (2007). The cellulose and SRFA had a similar ratio of $\mathrm{C} / \mathrm{N}$. Moreover, all the microbial residues had much less $\mathrm{C} / \mathrm{N}$ ratios but considerably more $\mathrm{H} / \mathrm{C}$ and $\mathrm{O} / \mathrm{C}$ ratios than SRHA and SRFA standards'.

\section{3 . FTIR analysis of microbial residues}

The FTIR spectra of different microbial residues were shown in Figure 3-6, respectively. The FTIR spectra of residue formed by $T v$ was presented in Figure 3 and their absorption peak intensities were listed in Table 4. An intense absorption peak at $3419 \mathrm{~cm}^{-1}(\mathrm{O}-\mathrm{H}$ stretching) (Zhang et al., 2011) primarily originated from cellulose. Two bands presented at 2926 and 2870 $\mathrm{cm}^{-1}$ were characteristic of aliphatic $\mathrm{C}-\mathrm{H}$ stretching (Droussi et al., 2009), the sum of their intensities had a downward trend. A shoulder peak at $1721 \mathrm{~cm}^{-1}$ attributed to $\mathrm{C}=\mathrm{O}$ stretching of $\mathrm{COOH}$ (Chai et al., 2007) appeared gradually with culture. The intensity of absorption peak at $1639 \mathrm{~cm}^{-1}$ weakened gradually, which associated with structural vibrations of aromatic $\mathrm{C}=\mathrm{C}$ and stretching of $\mathrm{COO}^{-}$groups. 
Table 1. Elemental compositions of microbial residues formed by three fungal species and mixed strains in the cellulose culture fluid during the inoculation period $(0-70 \mathrm{~d})$

\begin{tabular}{|c|c|c|c|c|c|}
\hline Microbial treatments & $\begin{array}{l}\text { Inoculation period } \\
\text { (d) }\end{array}$ & $\begin{array}{c}\text { Production rate }{ }^{a} \\
(\%)\end{array}$ & $\mathrm{C} / \mathrm{N}$ & $\mathrm{H} / \mathrm{C}$ & $\mathrm{O} / \mathrm{C}$ \\
\hline & 15 & $2.474 \pm 0.005 \mathrm{c}$ & $12.355 \pm 0.008 \mathrm{~b}$ & $1.921 \pm 0.005 \mathrm{~b}$ & $0.971 \pm 0.008 \mathrm{~b}$ \\
\hline \multirow[t]{3}{*}{$T v$} & 30 & $2.713 \pm 0.023 \mathrm{~b}$ & $14.005 \pm 0.010 \mathrm{a}$ & $2.060 \pm 0.005 \mathrm{a}$ & $1.203 \pm 0.005 \mathrm{a}$ \\
\hline & 70 & $2.952 \pm 0.071 \mathrm{aA}$ & $11.282 \pm 0.004 \mathrm{cC}$ & $1.881 \pm 0.004 \mathrm{cD}$ & $0.927 \pm 0.003 \mathrm{cE}$ \\
\hline & 15 & $1.120 \pm 0.002 \mathrm{~b}$ & $9.274 \pm 0.006 \mathrm{a}$ & $2.041 \pm 0.002 \mathrm{~b}$ & $1.110 \pm 0.003 \mathrm{a}$ \\
\hline \multirow[t]{3}{*}{$A n$} & 30 & $1.121 \pm 0.004 \mathrm{~b}$ & $8.071 \pm 0.009 \mathrm{~b}$ & $2.057 \pm 0.005 \mathrm{a}$ & $1.104 \pm 0.005 \mathrm{a}$ \\
\hline & 70 & $1.172 \pm 0.004 \mathrm{aC}$ & $7.543 \pm 0.005 \mathrm{cE}$ & $1.980 \pm 0.005 \mathrm{cC}$ & $0.992 \pm 0.002 \mathrm{bD}$ \\
\hline & 15 & $0.681 \pm 0.004 \mathrm{c}$ & $9.835 \pm 0.006 \mathrm{a}$ & $2.027 \pm 0.007 \mathrm{~b}$ & $1.123 \pm 0.002 \mathrm{~b}$ \\
\hline \multirow[t]{3}{*}{$P$} & 30 & $0.721 \pm 0.007 \mathrm{~b}$ & $9.427 \pm 0.009 \mathrm{~b}$ & $2.037 \pm 0.003 \mathrm{~b}$ & $1.124 \pm 0.004 \mathrm{~b}$ \\
\hline & 70 & $1.061 \pm 0.015 \mathrm{aD}$ & $8.699 \pm 0.005 \mathrm{cD}$ & $2.058 \pm 0.005 \mathrm{aB}$ & $1.157 \pm 0.004 \mathrm{aC}$ \\
\hline & 15 & $1.180 \pm 0.053 \mathrm{c}$ & $12.146 \pm 0.003 \mathrm{~b}$ & $2.032 \pm 0.003 \mathrm{~b}$ & $1.119 \pm 0.004 \mathrm{a}$ \\
\hline \multirow[t]{2}{*}{$M s$} & 30 & $1.320 \pm 0.005 \mathrm{~b}$ & $11.419 \pm 0.002 \mathrm{c}$ & $2.036 \pm 0.004 \mathrm{~b}$ & $1.180 \pm 0.004 \mathrm{~b}$ \\
\hline & 70 & $2.019 \pm 0.005 \mathrm{aB}$ & $12.475 \pm 0.005 \mathrm{aB}$ & $2.064 \pm 0.002 \mathrm{aB}$ & $1.255 \pm 0.003 \mathrm{cB}$ \\
\hline C & - & 0 (no data exist) & $88.130 \pm 0.035 \mathrm{~A}$ & $2.180 \pm 0.004 \mathrm{~A}$ & $1.310 \pm 0.002 \mathrm{~A}$ \\
\hline SRHA standard ${ }^{\mathrm{b}}$ & & & 52.63 & 1.00 & 0.61 \\
\hline SRFA standard ${ }^{b}$ & & & 83.33 & 0.98 & 0.60 \\
\hline
\end{tabular}

\footnotetext{
${ }^{a}$ Production rate $(\%)=($ amount of residue collected $/$ amount of cellulose added $) \times 100 \%$; Trichoderma viride $($ Tv $)$, Aspergillus niger $(A n)$, Penicillium $(P)$, Mixed strains $(M s)$, Cellulose sample $(C)$. According to Duncan's test, values (mean $\pm \operatorname{Std}$. Deviation) in a column followed by different lowercase and uppercase letters are statistically different within the different inoculation periods and treatments $(p<0.05)$ respectively. ${ }^{\text {b }}$ Suwannee River Humic Acid (SRHA) and Fulvic Acid (SRFA) Standards, which were obtained from the International Humic Substances Society (IHSS)-www.ihss.gatech.edu. Reference to Duarte et al., 2007.
}

Table 2. $F$ values for $\%$ production rate and $\mathrm{C} / \mathrm{N}, \mathrm{H} / \mathrm{C}, \mathrm{O} / \mathrm{C}$ ratio by the factors and interaction of inoculation period and microbial treatments

\begin{tabular}{cccccc}
\hline Factors & $\mathrm{df}$ & Production rate & $\mathrm{C} / \mathrm{N}$ & $\mathrm{H} / \mathrm{C}$ & $\mathrm{O} / \mathrm{C}$ \\
\hline Microbial treatment & 4 & $15190.267^{*}$ & $3.862 \mathrm{E} 7^{*}$ & $3302.255^{*}$ & $7448.250^{*}$ \\
Inoculation period & 2 & $852.361^{*}$ & $7840.022^{*}$ & $398.836^{*}$ & $1131.364^{*}$ \\
Inoculation period $\times$ Microbial treatment & 8 & $175.039^{*}$ & $6815.067^{*}$ & $353.261^{*}$ & $1368.981^{*}$ \\
\hline
\end{tabular}

$* p<0.05$ (LSD) 
Table 3. Results of multivariate test (MANOVA) ${ }^{\mathrm{c}}$

\begin{tabular}{|c|c|c|c|c|}
\hline Effect & & Value & $\mathrm{F}$ & Sig. \\
\hline \multirow[t]{4}{*}{ Intercept } & Pillai's Trace & 1.000 & $2.910 \mathrm{E} 7$ & 0.000 \\
\hline & Wilks's Lambda & 0.000 & $2.910 \mathrm{E} 7$ & 0.000 \\
\hline & Hotelling's Trace & 4311162.016 & $2.910 \mathrm{E} 7$ & 0.000 \\
\hline & Roy's Largest Root & 4311162.016 & $2.910 \mathrm{E} 7$ & 0.000 \\
\hline \multirow[t]{4}{*}{ Microbial treatment } & Pillai's Trace & 3.701 & 92.882 & 0.000 \\
\hline & Wilks's Lambda & 0.000 & 74901.597 & 0.000 \\
\hline & Hotelling's Trace & 6394235.309 & $1.019 \mathrm{E} 7$ & 0.000 \\
\hline & Roy's Largest Root & 6392848.569 & 4.795E7 & 0.000 \\
\hline \multirow[t]{4}{*}{ Inoculation period } & Pillai's Trace & 1.986 & 967.857 & 0.000 \\
\hline & Wilks's Lambda & 0.000 & $1517.938^{\mathrm{a}}$ & 0.000 \\
\hline & Hotelling's Trace & 730.726 & 2374.859 & 0.000 \\
\hline & Roy's Largest Root & 653.807 & $4576.651^{\mathrm{b}}$ & 0.000 \\
\hline \multirow[t]{4}{*}{ Inoculation period $\times$ Microbial treatment } & Pillai's Trace & 3.747 & 55.652 & 0.000 \\
\hline & Wilks's Lambda & 0.000 & 363.857 & 0.000 \\
\hline & Hotelling's Trace & 2965.647 & 2363.250 & 0.000 \\
\hline & Roy's Largest Root & 2832.418 & $10621.566^{\mathrm{b}}$ & 0.000 \\
\hline
\end{tabular}

a. Exact statistic. b.The statistic is an upper bound on F that yields a lower bound on the significance level. c. Design: Intercept ${ }^{+}$ Microbial treatment + Inoculation period + Inoculation period $\times$ Microbial treatment

The peak at $1061 \mathrm{~cm}^{-1}$ was characteristic of C-O stretching from carbohydrates (Droussi et al., 2009) or polysaccharide-like substances ( Fu and Quan, 2006), which could serve as a diagnostic approach of cellulose (Oliveira et al., 2009). The C-O stretching of phenolic groups and aryl esters could be detected at 1412 and $1251 \mathrm{~cm}^{-1}$, respectively. The complexes of carboxylic acid and metal ion from the cellulose nutrient fluid might result in a peak appearing around $1380 \mathrm{~cm}^{-1}$ (Fu and Quan, 2006).

There were some peaks with similar positions found in the residue treated by An (Figure 4). The vibration strengths of three peaks at 3414, 1326 and $1061 \mathrm{~cm}^{-1}$ weakened first and then strengened until the end.
However, the three absorption peaks at 2925, 2864 and $1412 \mathrm{~cm}^{-1}$ experienced a just opposite process. However, the three absorption peaks at 2925, 2864 and $1412 \mathrm{~cm}^{-1}$ experienced a just opposite process. Moreover, the peaks at 1721, 1644 and $1251 \mathrm{~cm}^{-1}$ had a decreasing trend. Finally, the peak at $1721 \mathrm{~cm}^{-1}$ disappeared.

The main absorption peaks of residue treated by $\mathrm{P}$ were marked in Figure 5. The changes of their relative intensities were as follows: the intensities of $3409,2926,2853$ and $1263 \mathrm{~cm}^{-1}$ were gradually strengthened, and the peak at $1721 \mathrm{~cm}^{-1}$ tended to disappear. The variations of 1648, 1387, 1324 and $1057 \mathrm{~cm}^{-1}$ reflected a common rule: decreasing slightly and later increasing significantly. 


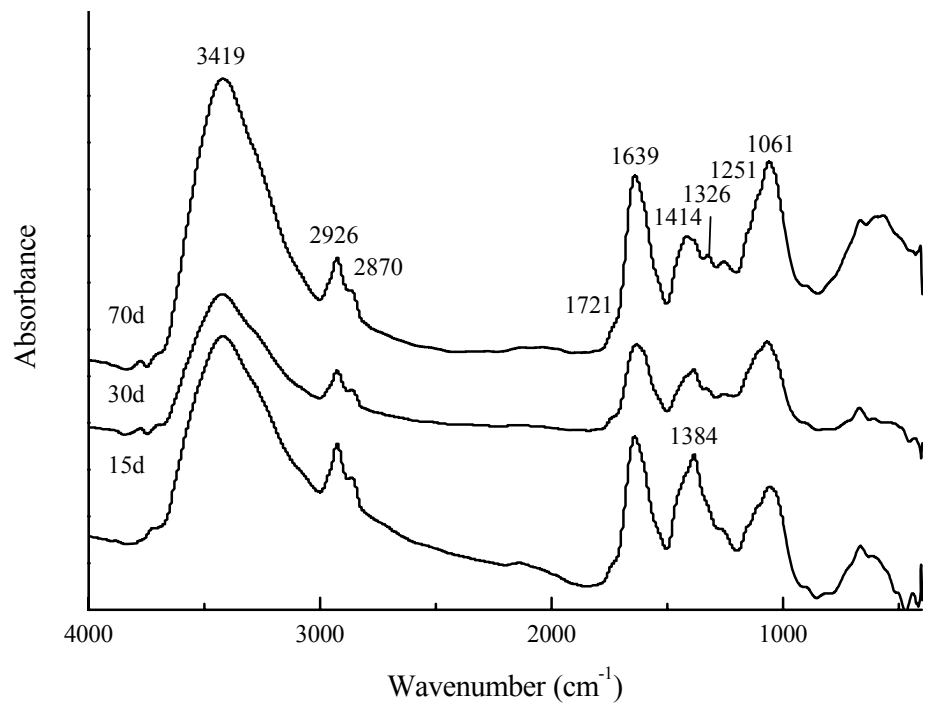

Figure 3. FTIR spectra of microbial residue formed by $T v$ in the cellulose culture fluid

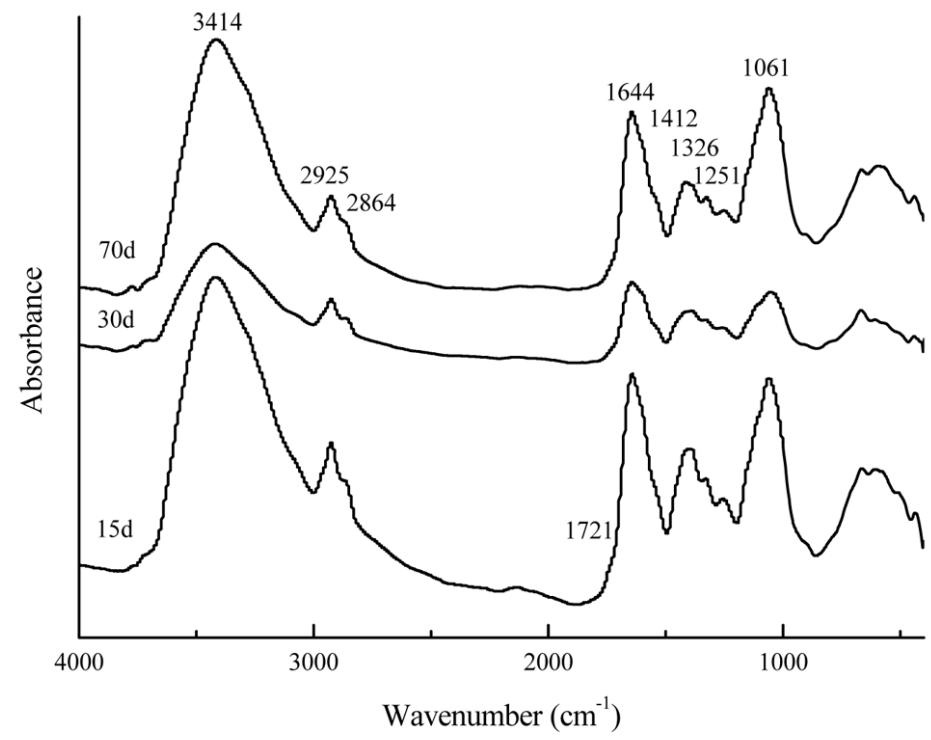

Figure 4. FTIR spectra of microbial residue formed by $A n$ in the cellulose culture fluid 


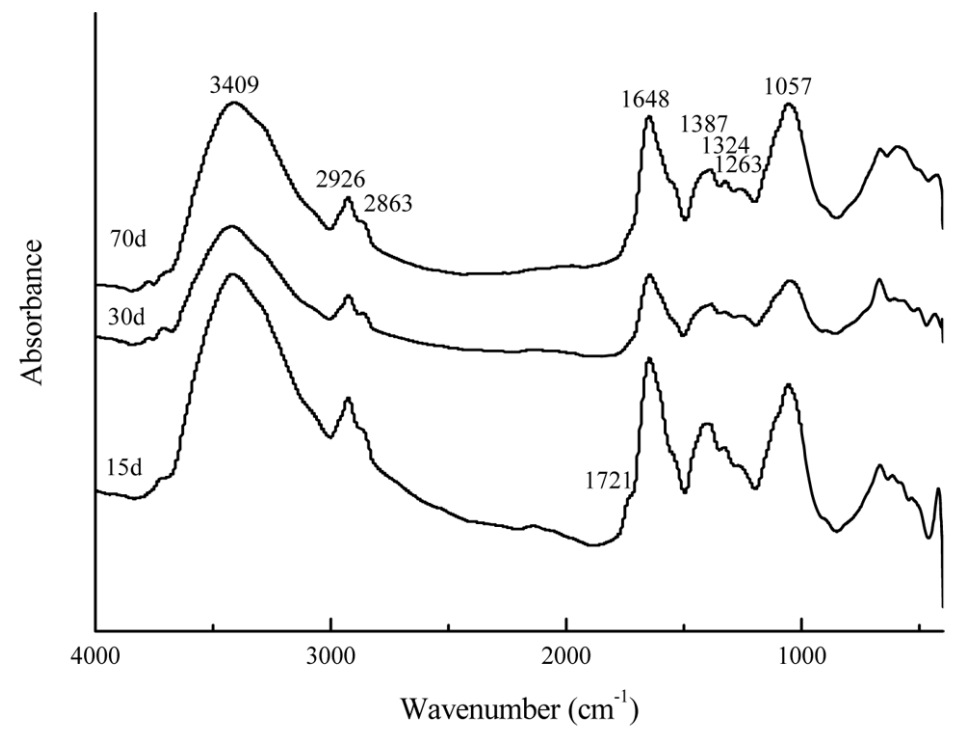

Figure 5. FTIR spectra of microbial residue formed by $P$ in the cellulose culture fluid

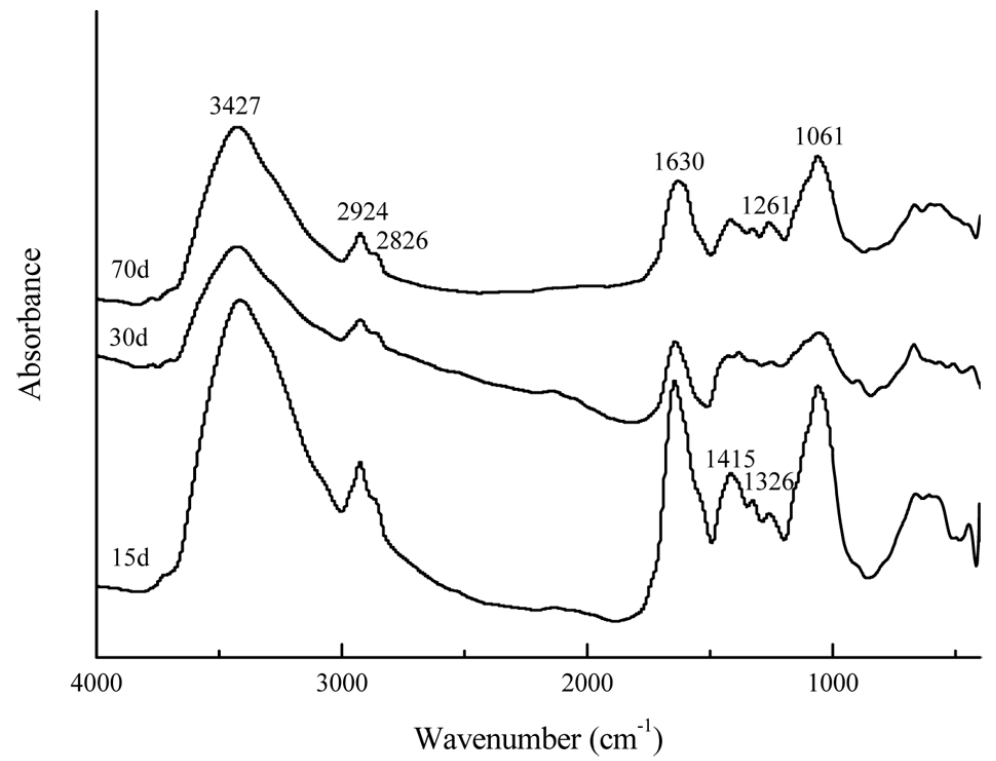

Figure 6. FTIR spectra of microbial residue formed by $M s$ in the cellulose culture fluid 
As was shown in Figure 6, with the incubation of $M S$, the intensities of absorption peaks at 3427, 2924, 1630, 1326 and $1061 \mathrm{~cm}^{-1}$ were all declined sharply at first and then enhanced just slightly. The peak intensities of 2826 and $1721 \mathrm{~cm}^{-1}$ remained the initial state without obvious change. The absorption band at 1415 $\mathrm{cm}^{-1}$ (C-O stretching of phenolic groups) (Droussi et al., 2009) appeared to increase first and decrease later, whose overall trend was downward. The exactly opposite rule was abide by a peak at $1261 \mathrm{~cm}^{-1}$.
In addition, the ratio of 2924/1630 was worthy of attention due to its role in evaluating the proportion of aliphatic $\mathrm{C}$ to aromatic $\mathrm{C}$. There was a decline trend of 2924/1630 ratio, from 0.190 to 0.154 , observed in the residue treated by $T v$. And the ratio from the $A n$ treatment was enhanced a little (0.144-0.190) and dropped by a large margin $(0.190-0.113)$. The changes of 2924/1630 ratios from the $P$ and $M s$ treatments shown a similar rule: increasing rapidly and declining slightly, whose overall levels were enhanced.

Table 4. The intensities of characteristic absorption peak of residues formed by different microbial strains in the cellulose fluid in different periods

\begin{tabular}{|c|c|c|c|c|c|c|c|c|c|c|c|}
\hline $\begin{array}{l}\text { Microbial } \\
\text { treatments }\end{array}$ & $\begin{array}{l}\text { Inoculation peried(d) } \\
\text { Inumber }\left(\mathrm{cm}^{-1}\right)\end{array}$ & $\begin{array}{l}3409 \\
-3427\end{array}$ & $\begin{array}{c}2924 \\
-2926^{a}\end{array}$ & $\begin{array}{c}2826 \\
-2897^{b}\end{array}$ & 1721 & $\begin{array}{r}1605 \\
-1648^{c}\end{array}$ & $\begin{array}{r}1387 \\
-1415\end{array}$ & $\begin{array}{r}1324 \\
-1326\end{array}$ & $\begin{array}{c}1251 \\
-1263\end{array}$ & $\begin{array}{r}1056 \\
-1061\end{array}$ & $(a+b) / c$ \\
\hline \multirow{3}{*}{$T v$} & 15 & 66.87 & 2.13 & 0.34 & - & 13.01 & 4.98 & 0.05 & 0.20 & 12.41 & 0.190 \\
\hline & 30 & 66.60 & 1.91 & 0.35 & 0.03 & 12.33 & 3.61 & 0.12 & 0.15 & 14.90 & 0.183 \\
\hline & 70 & 70.28 & 1.50 & 0.27 & 0.01 & 11.52 & 3.13 & 0.15 & 0.26 & 12.87 & 0.154 \\
\hline \multirow{3}{*}{$A n$} & 15 & 65.42 & 1.63 & 0.31 & 0.03 & 13.5 & 3.35 & 0.24 & 0.41 & 15.11 & 0.144 \\
\hline & 30 & 64.82 & 2.32 & 0.37 & 0.01 & 14.14 & 3.62 & 0.19 & 0.34 & 14.20 & 0.190 \\
\hline & 70 & 66.09 & 1.33 & 0.13 & - & 12.91 & 2.45 & 0.24 & 0.26 & 16.60 & 0.113 \\
\hline \multirow{3}{*}{$P$} & 15 & 10.57 & 0.26 & 0.05 & 0.02 & 2.23 & 0.61 & 0.04 & 0.05 & 2.52 & 0.139 \\
\hline & 30 & 12.12 & 0.37 & 0.06 & - & 2.22 & 0.57 & 0.03 & 0.08 & 2.28 & 0.194 \\
\hline & 70 & 14.38 & 0.38 & 0.07 & - & 2.99 & 0.71 & 0.06 & 0.08 & 3.74 & 0.151 \\
\hline \multirow{3}{*}{ Ms } & 15 & 15.71 & 0.37 & 0.06 & - & 3.50 & 0.73 & 0.06 & 0.12 & 3.94 & 0.123 \\
\hline & 30 & 11.94 & 0.27 & 0.06 & - & 2.02 & 0.92 & 0.02 & 0.05 & 1.94 & 0.163 \\
\hline & 70 & 14.97 & 0.34 & 0.06 & - & 2.62 & 0.50 & 0.05 & 0.23 & 3.31 & 0.153 \\
\hline$C$ & & 39.85 & - & 1.42 & - & 11.49 & 1.62 & 1.74 & 1.60 & 4.73 & - \\
\hline
\end{tabular}

Trichoderma viride (Tv), Aspergillus niger (An), Penicillium (P), Mixed strains (Ms), Cellulose sample (C). The 2924/1630 ratio was calculated as the ratio of a sum of intensities at 2924-2926 and 2826-2897 to a intensity at $1605-1648 \mathrm{~cm}^{-1}$, the letters a, b and c represented the vibration intensities of three peaks, respectively. 


\section{Discussion}

\subsection{Turnover of organic carbon}

The turnover of organic C was closed primarily as a result of the action of cellulose-utilizing microorganisms present in terrestrial and aquatic ecosystems (Lynd et al., 2002). The old system that cellulose serving as a sole $\mathrm{C}$ source was disrupted by the inoculation of different microbial suspensions containing a known amount of microbial biomass C. The microbial strains could become a powerful driving force for the conversion of organic C. During the incubation period (0-70 d), two major components were gradually formed in the new system: one was the cell metabolic product, the other was the microbial residue.

With the incubation proceeding, the amounts of microbial residues (Production rates were shown in Table 1) were all increased gradually, whose existences were more easily observable to the eye, simultaneously, the losses in organic $\mathrm{C}$ of cell metabolic products were significantly detected, especially $M s$, whose capacity of decomposition could achieve $71.02 \%$ of total merely in the short term (15 d). There were two ways used to explain the loss of organic $\mathrm{C}$ in the metabolic product: one way was the releasing of $\mathrm{CO}_{2}$ resulted from the microbial mineralization of cellulose, the other was the organic $\mathrm{C}$ conversion from the culture fluid into the microbial residues.

The degradation of microbial strains to cellulose in the fluid could make some intermediate products assimilated into microbial biomass while the other half was respired to form $\mathrm{CO}_{2}$ (Bai et al., 2013). The declined process of organic $\mathrm{C}$ in the cellulose fluid included two different phases, an initial rapid phase, in which easily available compounds were utilized, followed by a slower phase during which the more resistant fraction was decomposed. The utilization of water-soluble compounds in the first few days could provide the microbial strains more energy for releasing their enzymes (Marschner et al., 2011).
The microbial species differed in metabolic capacity when decomposing a given compound. In the aspect of utilizing organic $\mathrm{C}$ of metabolic products, $M S$ containing three different microbial communities had an advantage over the other three single fungal species. The possible reasons analyzed were as follows: Facing easily available compounds, the bacteria quickly dominate in the initial phase of decomposition due to their rapid reproduction rate, whereas the fungi grow more slowly than bacteria, but could decompose more recalcitrant material (Marschner et al., 2011). The actinomycetes with multicellular filaments usually had a moderate degradation to cellulose, although their ability was not as well as that of fungi.

Therefore, a reasonable co-culture of different species could play an overall benefit on the degradation of cellulose (Ma et al., 2011), and then provide a foundation for subsequent decomposition of compounds with more complex structures. However, among the three single fungal treatments, $T v$ had more capacity to compose the cellulose than the treatments of $P$ and $A n$ in the liquid. Microbial strains with their own features and adsorption characteristics made the treatments of $T v$ and $M s$ accumulate much more amount of residues than $A n$ and $P$.

\subsection{Compositions of microbial residues}

To characterize the chemical properties of HS, the atomic ratios were often used. The $\mathrm{H} / \mathrm{C}$ ratio was connected with the ratio of aliphatic/aromatic compounds (Chai et al., 2007), and the degree of dehydration or oxidation of HS could be estimated from $\mathrm{O} / \mathrm{C}$ value. To illustrate the similarities between microbial residues and HS, the atomic ratios were also applied to examine the properties of residues. The non-living microbial residues were bound up with HS formation and it could be also related to SOM turnover (Ding et al., 2011).

The atomic $\mathrm{C} / \mathrm{N}$ ratios (Table 1) for the microbial residues were, in general, much less than that of cellulose sample, thus suggesting a higher $\mathrm{N}$-containing 
materials existed in the residues compared to those of cellulose. It was so easy to understand that a part of inorganic $\mathrm{N}$ in the culture fluid could be assimilated into the microbial biomass, indirectly enhancing the amount of N-containing materials in its residue (Shindo and Nishio, 2005). The ability of utilizing inorganic $\mathrm{N}$ and synthesizing its own components of An in the fluid, by contrast, was the least. Compared with the cellulose, the $\mathrm{H} / \mathrm{C}$ and $\mathrm{O} / \mathrm{C}$ ratios of microbial residues were declined to varying degrees. It was indicated that the proportion of aromatic rings be enhanced at the cost of losing O-containing groups in the microbial residues.

The internal change from a single treatment with different inoculation periods should be carefully analyzed. Although the residue derived from $T V$ experienced a transient oxidation degradation process during the period of 15-30 d, its degree of condensation was finally enhanced, whereas the degree of oxidation was inhibited in the end. The $\mathrm{C} / \mathrm{N}, \mathrm{H} / \mathrm{C}$ and $\mathrm{O} / \mathrm{C}$ ratios of microbial residue treated by $A n$ had a downward trend during the incubation. That was because more condensed or substituted aromatic rings and $\mathrm{N}$-containing materials emerged in the microbial residue, however a low proportion of O-alkyl and carboxylic acid functional groups was reserved. The gradual decrease of $\mathrm{C} / \mathrm{N}$ ratio and slight increase of $\mathrm{H} / \mathrm{C}$ and $\mathrm{O} / \mathrm{C}$ ratios of the residue treated by $P$ were explained that the amounts of $\mathrm{N}$-containing (Large amounts of inorganic $\mathrm{N}$ were transferred into organic N components (Shindo and Nishio, 2005)) and aliphatic compounds, O-containing groups were enhanced gradually the least. Compared with the cellulose, the $\mathrm{H} / \mathrm{C}$ and $\mathrm{O} / \mathrm{C}$ ratios of microbial residues were declined to varying degrees. It was indicated that the proportion of aromatic rings be enhanced at the cost of losing O-containing groups in the microbial residues.

The internal change from a single treatment with different inoculation periods should be carefully analyzed. Although the residue derived from $T v$ experienced a transient oxidation degradation process during the period of 15-30 d, its degree of condensation was finally enhanced, whereas the degree of oxidation was inhibited in the end. The $\mathrm{C} / \mathrm{N}, \mathrm{H} / \mathrm{C}$ and $\mathrm{O} / \mathrm{C}$ ratios of microbial residue treated by $A n$ had a downward trend during the incubation. That was because more condensed or substituted aromatic rings and $\mathrm{N}$-containing materials emerged in the microbial residue, however a low proportion of O-alkyl and carboxylic acid functional groups was reserved. The gradual decrease of $\mathrm{C} / \mathrm{N}$ ratio and slight increase of $\mathrm{H} / \mathrm{C}$ and $\mathrm{O} / \mathrm{C}$ ratios of the residue treated by $P$ were explained that the amounts of $\mathrm{N}$-containing (Large amounts of inorganic $\mathrm{N}$ were transferred into organic N components (Shindo and Nishio, 2005)) and aliphatic compounds, O-containing groups were enhanced gradually cellulose. Furthermore, comparing with the referenced humic fractions (SRHA and SRFA standards), all the microbial residues originating from cellulose had more amounts of O-containing groups and $\mathrm{N}$-containing compounds, whereas their molecules were not polymerized the degree of real HS.

\subsection{FTIR spectra}

The main component of cellulose included a variety of hydroxyl and amino groups, which could be detected in the microbial residue with a noticeably broad peak at about $3409-3427 \mathrm{~cm}^{-1}$. Moreover, a characteristic peak at wave number of $1061 \mathrm{~cm}^{-1}$ in the spectrum was also found in the typical cellulose (Chen et al., 2013). The above results showed that the microbial residue obained still retained some structural features of cellulose, whose reason was that the cellulose was not fully transformed, or to say, the residual cellulose entered into the microbial residue.

As could be seen in the Table 3, the value of $(a+b) / c$ could indirectly respond to the relative proportion of aliphatic $\mathrm{C}$ to aromatic $\mathrm{C}$, which could be served as a good indicator of the degree of humification (Senesi et al., 1996). The change of $(\mathrm{a}+\mathrm{b}) / \mathrm{c}$ values told us the aromatic compounds in the residues treated by $T v$ and $A n$ emerged an increasing overall trend, which was 
consistent with the rule reflected by their $\mathrm{H} / \mathrm{C}$ ratios. Thus it could be seen that the incubations of $T v$ and $A n$ were helpful to enhance the recondensation of organic molecules obtained from the decomposition of cellulose.

On the contrary, the occurrence of degradation was confirmed by the gradually increased $\mathrm{H} / \mathrm{C}$ ratios of residues treated by $P$ and $M s$. As expected, their values of $(a+b) / c$ had a increasing overall trend, but there was a small peak appearing at $30 \mathrm{~d}$. It was inferred that the amounts of aliphatic compounds reach their maximums after the culture of $30 \mathrm{~d}$, and then a part of them could be degraded to $\mathrm{CO}_{2}$.

As one of the characteristic peaks, $1720 \mathrm{~cm}^{-1}$ assaigning to $\mathrm{C}=\mathrm{O}$ stretching of $\mathrm{COOH}$ and ketones was merely found in the residues treated by $T v$ and $A n$, actually their absorption intensions seemed rather weak. This allowed us to conclude that there was still a small number of differences existing in their structures between the microbial residues formed in the liquid and the real HS fractions, though the transformation of microbial residues into HS could be partly propelled by $T v$ and $A n$.

The peak at 1057 or $1061 \mathrm{~cm}^{-1}$ was assigned to the $\mathrm{C}-\mathrm{O}$ stretching vibration of carbohydrate structures. It was shown in the Table 3 that the vibration strengths of wave number at 1057 or $1061 \mathrm{~cm}^{-1}$ of residues treated by $P$ and $M s$ were weaker than cellulose', but their intenses from the other two microbial treatments ( $T v$ and $A n$ ) were stronger. The similar rules were also found around a broad band of 3409-3427 $\mathrm{cm}^{-1}$ and $1412 \mathrm{~cm}^{-1}$.

The oxydative degradation of residues treated by $P$ and $M s$, by rights, should have much more polysaccharides, which could strengthen the vibration intensity of the absorption peak at 1057 or $1061 \mathrm{~cm}^{-1}$. But it conflicted with the experimental results. On this basis, we guessed that the polysaccharides in the residues were possibly utilized again by the surplus living strains from the $P$ and $M s$. Amino sugar was the key compound of microbial cell walls (Bai et al., 2013 ), over $90 \%$ of which could be found in dead cells (Amelung et al., 2011). A large number of dead microbes from $T v$ and $A n$ could contribute to the enhancement of polysaccharide-like substances.

As compared to cellulose, the hydrogen bonds of $-\mathrm{OH}$ vibration from the residues were enhanced by $T v$ and $A n$. The free hydroxyl groups were the polar groups of noncrystalline molecular chain of cellulose. Their regular arrangement along the cellulose chain led to the formation of $\mathrm{H}$-bridges and therefore to a fibrillar structure with crystalline properties (Kögel-Knabner, 2002). Considered from this point, $T v$ and $A n$ were both helpful to the penetration of water solution into the noncrystalline region of residues, even could promote them dissolved slowly (Iyer et al., 1996; Laureano-Perez, 2005). On the contrary, $P$ and $M s$ were more beneficial to destroy the hydrogen bond from the intramolecular, intermolecular chains of residual crystalline region or between molecular chains and surface molecules, which could make the molecular structure of residue further collapsed and even be potentially vulnerable to degradation (Bayer and Lamed, 1992).

The amounts of phenolic compounds were enhanced remarkably in the residues treated by $T v$ and $A n$. It had been verified that the intensity of peak at around $1412 \mathrm{~cm}^{-1}$ be increased by the both treatments based on original cellulose.

Moreover, the change in the intensity of peak at around $1251 \mathrm{~cm}^{-1}$ suggested that nitration possibly occurred in the residues, which could affect their carboxylic groups. Those spectrum also exhibited a band at $1326 \mathrm{~cm}^{-1}$, which was usually attributed to the ring breathing vibrations of the syringyl units (Santos and Duarte, 1998). Although there were some micro-details detected, but these quantitative results could not convince us enough, at best, merely hint the existence of those ingredients. 


\section{Conclusions}

The incorporation of microbial suspensions into the cellulose fluid could induce a true priming effect. In the process, the microbial residue was rapidly formed, with a graduel loss in organic $\mathrm{C}$ of cell metabolic product, among which $M s$ performed the most effective role, $T v$ followed.

As compared to cellulose, large amounts of inorganic $\mathrm{N}$ in the fluid could be transferred into the organic N components of residue. Simultaneously, the proportion of aromatic rings could be increased at the cost of losing O-containing groups. Specifically, the enhanced degrees of condensation happened in the residues treated by $T v$ and $A n$, however their degrees of oxidation were inhibited. On the contrary, the $P$ and $M s$ treatments had a significant advantage in the oxydative degradation of cellulose. Although some intermediate products of HS could be detected in the microbial residues treated by $T v$ and $A n$, their organic molecules did not still achieve the polymerization degree of real HS. The non-living microbial residues were bound up with HS formation.

\section{Acknowledgements}

This research was funded by National Basic Research Program of China (National 973 Program) (2011CB100503). Moreover, we would like to thank Dr. Guixue Song for modifying and polishing my article.

\section{References}

Alam, M.Z., Fakhru'1-Razi, A., Abd-Aziz, S., Molla, A.H. 2003. Optimization of compatible mixed cultures for liquid state bioconversion of municipal wastewater sludge. Water, Air, and Soil Pollution, 149, 113-126.
Amelung, W., Miltner, A., Zhang, X., Zech, W. 2001. Fate of microbial residues during litter decomposition as affected by minerals. Soil Science. 166, 598-606.

Bai, Z., Bodé, S., Huygens, D., Zhang, X. D., Boeckx, P. 2013. Kinetics of amino sugar formation from organic residues of different quality. Soil Biology and Biochemistry. 57, 814-821.

Bayer, E.A., Lamed, R. 1992. The cellulose paradox: pollutant par excellence and/or a reclaimable natural resource. Biodegradation, 3 171-188.

Burdon, J. 2001. Are the traditional concepts of the structures of humic substances realistic. Soil Science. 166, 752-769.

Chai, X.L., Shimaoka, T., Cao, X.Y., Guo, Q., Zhao, Y.C. 2007. Spectroscopic studies of the progress of humification processes in humic substances extracted from refuse in a landfill. Chemosphere. 69. 1446-1453.

Chander, K., Joergensen, R.G. 2001. Decomposition of ${ }^{14} \mathrm{C}$ glucose in two soils with different levels of heavy metal contamination. Soil Biology and Biochemistry. 33, 1811-1816.

Chen, L., Hong, F., Yang, X.X., Han, S.F. 2013. Biotransformation of wheat straw to bacterial cellulose and its mechanism. Bioresource Technology, 135, 464-468.

Ding, X. L., Han, X. Z., Zhang, X. D., Qiao, Y. F. 2013. Effects of contrasting agricultural management on microbial residues in a Mollisol in China. Soil \& Tillage Research. 130, 13-17.

Ding, X L., He, H.B., Zhang, B., Zhang, X.D. 2011. Plant-N incorporation into microbial amino sugars as affected by inorganic $\mathrm{N}$ addition: A microcosm study of ${ }^{15} \mathrm{~N}$-labeled maize residue decomposition. Soil Biology and Biochemistry, 43,1968-1974. 
Droussi, Z., D'orazio, V., Hafidi, M., Ouatmane, A. 2009. Elemental and spectroscopic characterization of humic-acid-like compounds during composting of olive mill by-products. Journal of Hazardous Materials, 163, 1289-1297.

Duarte, R.M.B.O., Santos, E.B.H., Pio, C.A., Duarte, A.C. 2007. Comparison of structural features of water-soluble organic matter from atmospheric aerosols with those of aquatic humic substances. Atmospheric Environment. 41, 8100-8113.

Engelking, B., Flessa, H., Joergensen, R.G. 2007 a. Microbial use of maize cellulose and sugarcane sucrose monitored by changes in the ${ }^{13} \mathrm{C} /{ }^{12} \mathrm{C}$ ratio. Soil Biology and Biochemistry. 39,1888-1896.

Engelking, B., Flessa, H., Joergensen, R.G. $2007 \mathrm{~b}$. Shifts in amino sugar and ergosterol contents after addition of sucrose and cellulose to soil. Soil Biology and Biochemistry. 39, 2111-2118.

Fu, H.B., Quan, X. 2006. Complexes of fulvic acid on the surface of hematite, goethite, and akaganeite: FTIR observation. Chemosphere. 63, 403-410.

Iyer, P.V., Wu, Z.W., Kim, S.B., Lee, Y.Y. 1996. Ammonia Recycled percolation Process for Pretreatment of Herbaceous Biomass. Applied Biochemistry and Biotechnology. 57-58, 121-132.

Kögel-Knabner I. 2002. The macromolecular organic composition of plant and microbial residues as inputs to soil organic matter. Soil Biology and Biochemistry. 34, 139-162.

Kosobucki, P., Buszewski, B. 2011. Carbon changes in environment, from tatal organic caibon to soil organic matter. Polish Journal of Environmental Studies. 20, 9-14.

Laureano-Perez, L. 2005. Spectroscopic and chemical characterization of biomass. Dissertation, Michigan State University.
Lynd, L.R., Weimer, P.J., van Zyl, W.H., Pretorius, I.S. 2002. Microbial cellulose utilization: fundamentals and biotechnology. Microbiology and Molecular Biology Reviews. 66, 506-577.

Ma, F.Y., Wang, J.J., Zeng, Y.L., Yu, H.B., Yang, Y., Zhang, X.Y. 2011. Influence of the co-fungal treatment with two white rot fungi on the lignocellulosic degradation and thermogravimetry of corn stover. Process Biochemistry. 46, 1767-1773.

Marschner, P., Umar, S., Baumann, K. 2011. The microbial community composition changes rapidly in the early stages of decomposition of wheat residue. Soil Biology and Biochemistry. 43, 445-451.

McDonald, S., Bishop, A.G., Prenzler, P.D., Robards, K. 2004. Analytical chemistry of freshwater humic substances. Analytica Chimica Acta. 527, 105-124.

Oliveira, H., Barros, A.S., Delgadillo, I., Coimbra, M. A., Santos, C. 2009. Effects of fungus inoculation and salt stress on physiology and biochemistry of in vitro grapevines: Emphasis on sugar composition changes by FT-IR analyses. Environmental and Experimental Botany. 65, 1-10.

Santos, E.B.H., Duarte, A.C. 1998. The influence of pulp and paper mill effluents on the composition of the humic fraction of aquatic organic matter. Water Resources. 32, 597-608.

Senesi, N., Miano, T., Brunetti, G. 1996. Humic-like substances in organic amendments and effects on native soil humic substances, In: Humic Substances in Terrestrial Ecosystems 14 edn (Piccolo, A., eds.). Elsevier, Amsterdam, Netherlands. pp:531-593.

Shindo, H., Nishio, T. 2005. Immobilization and remineralisation of $\mathrm{N}$ following addition of wheat straw into soil: determination of gross $\mathrm{N}$ transformation rates by ${ }^{15} \mathrm{~N}$-ammonium isotope dilution technique. Soil Biology and Biochemistry., 37, 425-432. 
Singh, A., Sharma, S. 2002. Composting of a crop residue through treatment with microorganisms and subsequent vermicomposting. Bioresource Technology. 85, 107-111.

Vinten, A.J.A., Whitmore, A.P., Bloem, J., Howard, R., Wright, F. 2002. Factors affecting N immobilisation/mineralisation kinetics for cellulose-, glucose- and straw-amended sandy soils. Biology and Fertility of Soils. 36, 190-199.
Zhang, J.J., Hu, F., Li, H.X., Gao, Q., Song, X.Y., Ke, X.K., Wang, L.C. 2011. Effects of earthworm activity on humus composition and humic acid characteristics of soil in a maize residue amended rice-wheat rotation agroecosystem. Applied Soil Ecology. 51, 1-8. 